\title{
Antioxidant Responses and Gene Expression in Bermudagrass under Cold Stress
}

\author{
Jibiao Fan and Jing Ren \\ Key Laboratory of Plant Germplasm Enhancement and Specialty Agriculture and Wuhan Botanical \\ Garden, Chinese Academy of Sciences, Wuhan, Hubei 430074, China; and the University of Chinese \\ Academy of Sciences, 19 Yuquan Road, Beijing 100049, China \\ Weixi Zhu \\ Key Laboratory of Plant Germplasm Enhancement and Specialty Agriculture and Wuhan Botanical \\ Garden, Chinese Academy of Sciences, Wuhan, Hubei 430074, China \\ Erick Amombo \\ Key Laboratory of Plant Germplasm Enhancement and Specialty Agriculture and Wuhan Botanical \\ Garden, Chinese Academy of Sciences, Wuhan, Hubei 430074, China; and the University of Chinese \\ Academy of Sciences, 19 Yuquan Road, Beijing 100049, China \\ Jinmin $\mathrm{Fu}^{1}$ and Liang Chen ${ }^{1}$ \\ Key Laboratory of Plant Germplasm Enhancement and Specialty Agriculture and Wuhan Botanical \\ Garden, Chinese Academy of Sciences, Wuhan, Hubei 430074, China \\ Additional INDEX words. Cynodon dactylon, low temperature, physiology, membrane stability, reactive oxygen species

\begin{abstract}
Cold stress is a key factor limiting resource use in bermudagrass (Cynodon dactylon). Under cold stress, bermudagrass growth is severely inhibited and the leaves undergo chlorosis. Therefore, rigorous investigation on the physiological and molecular mechanisms of cold stress in this turf species is urgent. The objective of this study was to investigate the physiological and molecular alteration in wild bermudagrass under cold stress, particularly the changes of transpiration rate, soluble sugar content, enzyme activities, and expression of antioxidant genes. Wild bermudagrass (C. dactylon) was planted in plastic pots (each $10 \mathrm{~cm}$ tall and $8 \mathrm{~cm}$ in diameter) filled with matrix (brown coal soil:sand 1:1) and treated with $4{ }^{\circ} \mathrm{C}$ in a growth chamber. The results displayed a dramatic decline in the growth and transpiration rates of the wild bermudagrass under $4{ }^{\circ} \mathrm{C}$ temperature. Simultaneously, cold severely destabilized the cell membrane as indicated by increased malondialdehyde content and electrolyte leakage value. Superoxide dismutase and peroxidase activities were higher in the cold regime than the control. The expression of antioxidant genes including $\mathrm{MnSOD}, \mathrm{Cu} / \mathrm{ZnSOD}, P O D$, and $A P X$ was vividly up-regulated after cold stress. In summary, our results contributed to the understanding of the role of the antioxidant system in bermudagrass' response to cold.
\end{abstract}

Bermudagrass is widely used in the turf systems and is equally relevant in animal husbandry because of its high protein content and relatively low cost. Bermudagrass is a typical warm-season grass, which grows best under air temperature ranging from 29.4 to $37.8^{\circ} \mathrm{C}$ and soil temperature ranging from 23.9 to $35{ }^{\circ} \mathrm{C}$. The minimum air temperature required for growth is $12.8{ }^{\circ} \mathrm{C}$ (Zhou, 1996). Therefore, below optimum temperature is a significant factor that may limit resource use in bermudagrass. Low temperature can influence growth, development, and yield of botanical species (Zhu et al., 2007). Hughes and Dunn (1996) reported that when exposed to low but not freezing temperature, plants can obtain chilling and freezing tolerance (cold acclimation) (Hughes and Dunn, 1996). Some studies have reported that cold stress led to biochemical and physical changes in plants, particularly causing freezing injury, which was accounted for by the damage on the plasma

Received for publication 25 June 2014. Accepted for publication 26 Sept. 2014. This research was financially supported by National Natural Science Foundation of China (Grant nos. 31272194 and 31101563 ) and China-Africa Center for Research and Education (Grant no. SAJC201325).

${ }^{1}$ Corresponding authors. E-mail: chenliang1034@126.com,jinminfu@gmail. com. membrane. Other studies found that low temperature damaged cell membrane systems and lipid peroxidation by decreasing the fluidity of cell membranes of most plants (Levitt, 1980).

Malondialdehyde (MDA) and electrolyte leakage (EL) served as indicators of lipid peroxidation. Södergren (2000) reported that MDA was higher under low-temperature conditions (Södergren, 2000). In Forsythia species treated at $4{ }^{\circ} \mathrm{C}$, MDA contents increased by $\approx 66.7 \%$ (Yan et al., 2010). Similarly, MDA levels were higher in wheat (Triticum aestivum) seedlings and strawberry (Fragaria ananassa) leaves subjected to 4 and $0{ }^{\circ} \mathrm{C}$, respectively (Hou et al., 2010; Luo et al., 2011). Electrical conductivity is widely applied to detect membrane injury caused by various biotic and abiotic stresses in plants (Whitlow et al., 1992). EL declined in bermudagrass cultivars after $8{ }^{\circ} \mathrm{C}$ day temperature and $4{ }^{\circ} \mathrm{C}$ night temperature cold acclimation (Zhang et al., 2006). EL of leaves significantly increased by $55 \%$ and $26.3 \%$ in naked oats (Avena nuda) treated by -10 and $1{ }^{\circ} \mathrm{C}$, respectively (Liu et al., 2013), indicating that low temperature could affect cell membrane penetrability.

Sufficient evidence suggests that extremely low temperature can induce oxidative stress through the generation of reactive 
oxygen species (ROS) in plants (Yan et al., 2010). Reactive oxygen species damage many vital cellular components such as lipids, proteins, and DNA (Södergren, 2000). Reactive oxygen species could be scavenged by enzymatic detoxification mechanisms consisting of superoxide dismutase (SOD), peroxidase (POD), and catalase (CAT) (Asada, 2006; Gupta et al., 1993; Kono and Fridovich, 1982). SOD including copper/zinc $(\mathrm{Cu} /$ ZnSOD), manganese (MnSOD), and iron (FeSOD) catalyzes the superoxide free radical ion to $\mathrm{H}_{2} \mathrm{O}_{2}$ according to the equation: $2 \mathrm{O}_{2}^{-}+2 \mathrm{H}^{+} \rightarrow \mathrm{H}_{2} \mathrm{O}_{2}+\mathrm{O}_{2}$.

Superoxide dismutase content increased during the first $7 \mathrm{~d}$ and then declined, whereas CAT and ascorbate peroxidase (APX) activity decreased when bermudagrass was subjected to $8 / 4{ }^{\circ} \mathrm{C}$ (day/night) temperature (Zhang et al., 2006). SOD activity increased dramatically in Euonymus radicans (Guo et al., 2004) and Citrus species (C. unshiu, C. sinensis, C. limon) by prolonged exposure to cold treatment (Mohammadian et al., 2012). POD is also an essential enzyme in plant response to abiotic stress by reducing hydrogen peroxides through energy transfer from reactive peroxides to glutathione. Rice (Oryza sativa) treated with $6{ }^{\circ} \mathrm{C}$ temperature had a $56 \%$ to $72 \%$ higher level of POD activity than the control (Wang and Cai, 2011). APX exists as an isoenzyme and is vital for catalyzing of $\mathrm{H}_{2} \mathrm{O}_{2}$ reduction in higher plants. APX activity in strawberry leaves was also elevated after low temperature $\left(0{ }^{\circ} \mathrm{C}\right.$ ) for $72 \mathrm{~h}$ (Luo et al., 2011). Another crucial enzyme necessary for $\mathrm{H}_{2} \mathrm{O}_{2}$ decomposition in plant tissues is CAT (Brian et al., 1984). Luo et al. (2011) reported that CAT activity increased in strawberry (Luo et al., 2011). However, APX subjected to $3{ }^{\circ} \mathrm{C}$ equaled that of the control where leaves were exposed to $15{ }^{\circ} \mathrm{C}$ in the dark for $24 \mathrm{~h}$ in cucumber (Cucumis sativus) cultivars (Shen et al., 1999). These observations suggested that CAT response might depend on species, cold duration, and other undocumented factors. Previous research suggests that oxidative stress as indicated by lipid peroxidation may occur when ROS production overwhelms the active oxygen species scavenging (Mittler, 2002).

Alterations in enzymatic detoxification mechanisms correlated positively with the expression of corresponding genes (Levitt, 1980). Elevated cold tolerance can be accompanied by the increase in expression of specific genes encoding antioxidant enzymes (Baek and Skinner, 2003). Kayihan et al. (2012) investigated the effects of cold acclimation and freezing on $\mathrm{Cu}$ / Zn superoxide dismutase activity and respective gene expression in barley (Hordeum vulgare) cultivars and found that leaf $\mathrm{Cu} / \mathrm{ZnSOD}$ expression levels were unchanged during cold acclimation but increased evidently at $-3{ }^{\circ} \mathrm{C}$ freezing stress. Seedling leaves of manioc (Jatropha curcas) subjected to chilling shock exhibited a higher level of SOD, APX, CAT, and glutathione reductase than the control (Ao et al., 2013).

Most studies on the effects of cold on bermudagrass have focused on growth and antioxidant enzyme activities. Therefore, there was insufficient information on the combined mechanism of antioxidant enzyme activity and gene expression levels. A chitinase gene of bermudagrass CynCHT1 was reported in revolving freezing tolerance (Anderson et al., 2005). This implies that studies on mechanisms of response to cold stress in bermudagrass are limited; therefore, more investigation is mandatory. Consequently, the mechanism of antioxidant metabolism contribution to bermudagrass adaptation to low temperature is undocumented. Therefore, the comprehension of antioxidative metabolic responses to cold will improve our understanding of the contribution of biochemical mechanisms under low temperature to resistance in bermudagrass. Thus, the objective of this study was to investigate the physiological and molecular alteration in wild bermudagrass under cold stress, particularly the changes of transpiration rate, soluble sugar content, enzyme activities, and expression of antioxidant genes.

\section{Materials and Methods}

Plant materials and growth Conditions. Bermudagrass used in this study was collected from wild fields of Jiangsu province, China. Preliminary study confirmed that the specimen was cold-sensitive. On 20 Sept. 2013, 30 stolons were planted in plastic pots (each $10 \mathrm{~cm}$ tall and $8 \mathrm{~cm}$ in diameter) filled with matrix ( 1 brown coal soil:1 sand). Drainage holes ( $5 \mathrm{~mm}$ in diameter) were drilled at the bottom of each pot to allow drainage of excess water and soil aeration. All pots were kept in a greenhouse with the daily maximum/minimum temperatures of $31 / 23{ }^{\circ} \mathrm{C}$ (day/night), the average temperature was $\approx 27^{\circ} \mathrm{C}$, relative humidity was $40 \%$, pan evaporation rate was $9.5 \mathrm{~g} \cdot \mathrm{d}^{-1}$, and the photoperiod was $12 \mathrm{~h}$. Light intensity on a horizontal plane above the canopy at $1200 \mathrm{HR}$ averaged $240 \mu \mathrm{mol} \cdot \mathrm{m}^{-2} \cdot \mathrm{s}^{-1}$ photosynthetically active radiation $(P A R)$.

Plants were grown in the pots for $14 \mathrm{~d}$, which allowed grass to establish. During the 21-d period, plants were watered with $100 \mathrm{~mL}$ until water drained freely from the drainage holes at the bottom of each pot. Plants were fertilized daily with full-strength Hoagland nutrient solution (Hoagland and Arnon, 1950).

Treatments. The experiment consisted of two temperature treatments: the control and low-temperature treatment. Under the control, optimum temperature was maintained in the greenhouse. Under low-temperature treatment, plants were kept in a growth chamber (LSC-339CF; Xingxing Group Co., Zhejiang, China) on 9 Oct. 2013 with a temperature of $4{ }^{\circ} \mathrm{C}$, relative humidity was $40 \%$, pan evaporation rate was $6 \mathrm{~g} \cdot \mathrm{d}^{-1}$, and the photoperiod was $12 \mathrm{~h}, 240 \mu \mathrm{mol} \cdot \mathrm{m}^{-2} \cdot \mathrm{s}^{-1} P A R$. Fully extended leaf samples were collected at the beginning (denoted as Day 0), after low-temperature treatment at Days 1 and 3 for physiological analysis, and at $0,1,3,6,12,24,48$, and $72 \mathrm{~h}$ for gene expression analysis. Harvested leaves were put in liquid nitrogen immediately and then stored at $-80{ }^{\circ} \mathrm{C}$ in a refrigerator until physiological and gene expression analysis. To detect the growth alteration of bermudagrass under cold stress, the growth and evapotranspiration rate were measured with the same condition on 8 Jan. 2014.

Measurements. Growth rate was determined as the difference in canopy height at 0,7 , and $14 \mathrm{~d}$ after treatment. The precision-cut square paper was set on the top of the plant canopy, and the distance between the paper and the plant base was measured with a ruler every $3 \mathrm{~d}$. Canopy vertical height was measured in four directions of the paper. The growth rate was the increment of the growth per day.

To determine the evapotranspiration of the plants, the plantpot system was weighed before treatment began and then reweighed $2 \mathrm{~d}$ after treatment. A decrease in plant-pot system weight was considered as the evapotranspiration rate. The evapotranspiration rate calculated at Days 7 and 14, respectively.

EL was measured by the following procedure: $0.1 \mathrm{~g}$ of fully developed leaves were excised from the plants and washed three times with deionized water. The leaves were cut to $\approx 0.5-\mathrm{cm}$ fragments, transferred into a $50-\mathrm{mL}$ centrifuge 
tube filled with $15 \mathrm{~mL}$ deionized water, and then shaken for $24 \mathrm{~h}$ at room temperature. The initial conductivity was measured using a conductivity meter. The solutions were autoclaved at $121{ }^{\circ} \mathrm{C}$ for $10 \mathrm{~min}$ to make the tissues release all the electrolytes. The conductivity was determined after cooling the solution at room temperature. The ratio of the two conductivity values was the relative EL.

For the antioxidative gene expression analysis, total RNA was extracted with Trizol reagent (Invitrogen, Carlsbad, CA) according to the user manual predigested with DNase I to eliminate the genomic DNA. First-strand cDNA was synthesized using M-MLV reverse transcriptase (Promega, Madison, WI) with an oligo(dT) primer and directly subjected to template for reverse transcription-polymerase chain reaction (RT-PCR) analysis. Gene expression was then analyzed by real-time quantitative reverse transcriptase RT-PCR using gene specific primers (Table 1); fluorescent dye SYBR Green (Toyobo, Osaka, Japan) was applied in the detection system. Real-time PCR reaction was performed using the Real-time PCR Master Mix (Toyobo) according to the manual. The Actin gene was used as an internal control to normalize the data. Relative quantity of the target gene expression level was performed using the comparative $\mathrm{Ct}$ method (Chen et al., 2011).

For crude anti-oxidative enzyme extraction, $0.3 \mathrm{~g}$ of fresh leaves were ground to a fine powder in liquid nitrogen and then mixed with $4 \mathrm{~mL}$ sodium phosphate buffer (150 mM, $\mathrm{pH} 7.0)$ and treated with pre-cooling at $4{ }^{\circ} \mathrm{C}$. The homogenate was transferred into a $10-\mathrm{mL}$ centrifuge tube and then centrifuged for $20 \mathrm{~min}$ with $13,523 \mathrm{~g}_{\mathrm{n}}$ at $4{ }^{\circ} \mathrm{C}$. The supernatant was the crude enzyme solution.

MDA content was measured by thiobarbituric acid (TBA) method with slight modifications described by Heath and Packer (1968). Crude enzyme extract (1 mL) was mixed with $2 \mathrm{~mL}$ MDA reaction buffer consisting of $0.5 \%(\mathrm{v} / \mathrm{v}) \mathrm{TBA}$ and $20 \%(\mathrm{v} / \mathrm{v})$ trichloroacetic acid. The mixture was heated in a water bath at $95{ }^{\circ} \mathrm{C}$ for $30 \mathrm{~min}$, refrigerated at room temperature, and then centrifuged for $10 \mathrm{~min}$ with $13,523 \mathrm{~g}_{\mathrm{n}}$ at $20^{\circ} \mathrm{C}$. The absorbance of the supernatant at 532 and $600 \mathrm{~nm}$ was measured using a spectrophotometer. The MDA content was calculated with the formula: MDA (nanomoles per gram) = $[(\mathrm{OD} 532-\mathrm{OD} 600) \times \mathrm{L}] /(1 \times \varepsilon \times \mathrm{FW})$ where $\mathrm{L}$ indicates the volume of the extract solution, 1 indicates thickness of the cuvettes, $\varepsilon$ represents the molar absorption coefficient of $155 \mathrm{~mm}^{-1} \cdot \mathrm{cm}^{-1}$, and FW is the fresh weight of the leaf tissue.

SOD activity was measured based on Giannopolitis and Ries (1977) method. One milliliter of crude enzyme solution was

Table 1. Primers used for expression of antioxidase genes in bermudagrass.

\begin{tabular}{|c|c|c|}
\hline \multicolumn{2}{|l|}{ Gene name } & Primer sequences \\
\hline \multirow[t]{2}{*}{$A P X$} & $F$ & 5' CCTGAAAGGTCTGGGTTTGA 3' \\
\hline & $\mathrm{R}$ & $5^{\prime}$ TCCTTGGCATAAAGGTCCAC 3' \\
\hline \multirow[t]{2}{*}{$\mathrm{Cu} / \mathrm{ZnSOD}$} & $\mathrm{F}$ & 5' GACACMACAAATGGHTGCAT 3' \\
\hline & $\mathrm{R}$ & $5^{\prime}$ TCATCBGGATCGGCATGGACAAC 3' \\
\hline \multirow[t]{2}{*}{$M n S O D$} & $\mathrm{~F}$ & 5' CAGRGBGCCATCAAGTTCAACG 3' \\
\hline & $\mathrm{R}$ & 5' TACTGCAGGTAGTACGCATG 3' \\
\hline \multirow[t]{2}{*}{$P O D$} & $\mathrm{~F}$ & $5^{\prime}$ AGGCCCAGTGCTHCAMCTTC 3' \\
\hline & $\mathrm{R}$ & 5' TTGGTGTAGTAGGCGTTGTC 3' \\
\hline \multirow[t]{2}{*}{$C A T$} & $\mathrm{~F}$ & 5' GGCTGGTTCCTTTCGTTT 3' \\
\hline & $\mathrm{R}$ & 5' TCGGTTTCATTTGGCTGT 3' \\
\hline
\end{tabular}

$\mathrm{F}=$ forward; $\mathrm{R}=$ reverse. mixed with $2.2 \mathrm{~mL} 50 \mathrm{~mm}$ sodium phosphate buffer ( $\mathrm{pH} 7.8$ ), $0.012 \mu \mathrm{M}$ riboflavin, $0.039 \mathrm{~mm}$ methionine, $0.3 \mathrm{nM}$ ethylene diaminetetraacetic acid, $0.225 \mu \mathrm{M}$ nitro blue tetrazolium (NBT), and $3 \mathrm{~mL}$ reaction solution without crude enzyme solution as a control. The mixture was illuminated under a 4000-lx fluorescent lamp chromogenic React for $60 \mathrm{~min}$ and then the absorbance tested at $560 \mathrm{~nm}$. The enzyme quantity that reduced NBT by $50 \%$ under the dark condition was regarded as the control.

POD activity was determined by the method described by Chance and Maehly (1955). Fifty microliters of crude enzyme solution were added into the reaction solution containing $0.25 \mathrm{~mL}$ guaiacol (guaiacol was dissolved in 50\% ethanol solution), $0.075 \mathrm{~mL} \mathrm{H}_{2} \mathrm{O}_{2}$, and $1.85 \mathrm{~mL}$ sodium acetate-acetic acid buffer ( $\mathrm{pH}$ 5.0). Absorbance increase at $460 \mathrm{~nm}$ was measured after $3 \mathrm{~min}$. Change of one unit per minute of the absorbance was defined as one unit POD activity.

Soluble sugars were measured by the following procedure: leaf samples $(1.5 \mathrm{~g})$ were cut into pieces and put in a $10-\mathrm{mL}$ centrifuge tube filled with $8 \mathrm{~mL}$ deionized water. The mixture was inserted in water bath at $100{ }^{\circ} \mathrm{C}$ for $1 \mathrm{~h}$. After cooling to room temperature, the extract solution was centrifuged at $845 g_{n}$ for $30 \mathrm{~min}$. Five hundred microliters of supernatant were mixed with $4 \mathrm{~mL}$ anthrone reagent $(0.2 \mathrm{~g}$ anthrone dissolved into $0.1 \mathrm{~L} 80 \%$ sulfuric acid solution) and inserted in a water bath at $100{ }^{\circ} \mathrm{C}$ for $10 \mathrm{~min}$. The mixture was cooled to room temperature and the absorbance of the mixture detected at $620 \mathrm{~nm}$. Each sample was repeated three times.

EXPerimental Design and STATistical anAlysis. The experiment was arranged in a completely randomized design with three replications. The data analysis was done by SPSS software (Version 14.0; IBM Corp., Armonk, NY). The data displayed are the means $\pm \mathrm{SD}$, and the mean was the average of three replicates. Independent tests for equality of means demonstrated that there was a significant difference $(P<$ 0.05 ) between the control and the treatment.

\section{Results}

Growth rate was $\approx 74.8 \%$ and $76.6 \%$ lower at Days 7 and 14 in the cold-treated plant than the control, respectively (Fig. 1A). However, no significant difference in relative growth rate was observed between two measuring dates regardless of treatment. Bermudagrass subjected to $4{ }^{\circ} \mathrm{C}$ temperature had a 6-fold lower transpiration rate compared with the control (Fig. 1B). Transpiration rate slightly declined at Days 7 to 14 when bermudagrass was subjected to $4{ }^{\circ} \mathrm{C}$.

MDA content was $65 \%$ and $32 \%$ higher at Days 1 and 3 for the $4{ }^{\circ} \mathrm{C}$ regime than the control, respectively (Fig. 2A). Bermudagrass treated at $4{ }^{\circ} \mathrm{C}$ had a $19.6 \%$ and $47.4 \%$ higher EL than that of control at Days 1 and 3, respectively (Fig. 2B).

SOD activity was $122 \%$ and $41.8 \%$ higher at Days 1 and 3 , respectively, for the cold regime than the control (Fig. 3A). Prolonged cold treatment (Day 3 ) resulted in more reduction in SOD activity. Similarly, under cold stress, the POD activity was $185.6 \%$ and $185.5 \%$ higher at Days 1 and 3, respectively, than that in the control (Fig. 3B). No significant difference in POD activity was observed between Days 1 and 3 .

Low temperature induced a significant increase in soluble sugars content. Soluble sugar content was $133.3 \%$ and $267.6 \%$ higher at Days 1 and 3, respectively, for $4{ }^{\circ} \mathrm{C}$ treated bermudagrass than untreated plants (Fig. 4). Bermudagrass contained 

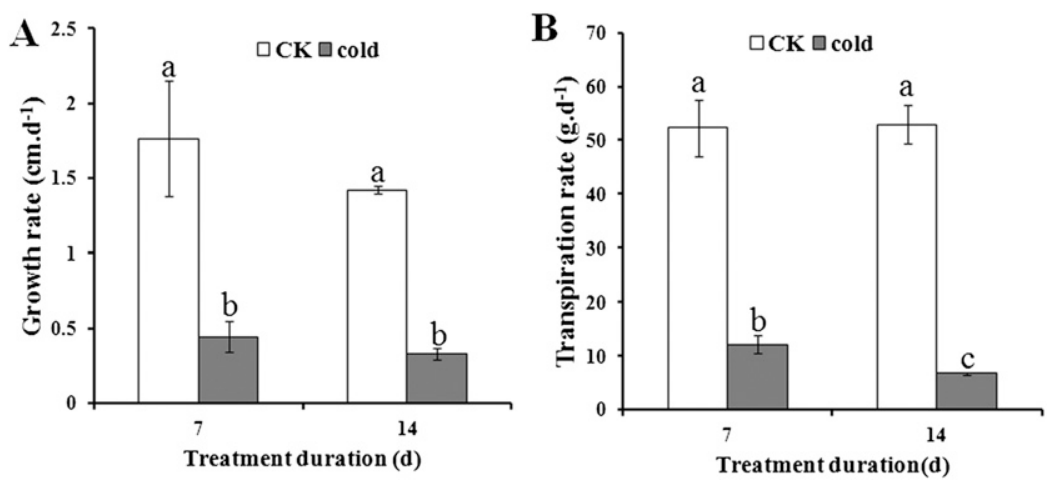

Fig. 1. Growth rate $(\mathbf{A})$ and transpiration rate $(\mathbf{B})$ of bermudagrass under cold stress. Experiments were repeated four times. Independent-samples $t$ test was used to determine statistical differences. Bars show SD. Different letters indicate statistical difference significance at $P<0.05$ among the treatments. $\mathrm{CK}=$ control; cold $=4{ }^{\circ} \mathrm{C}$ treatment.
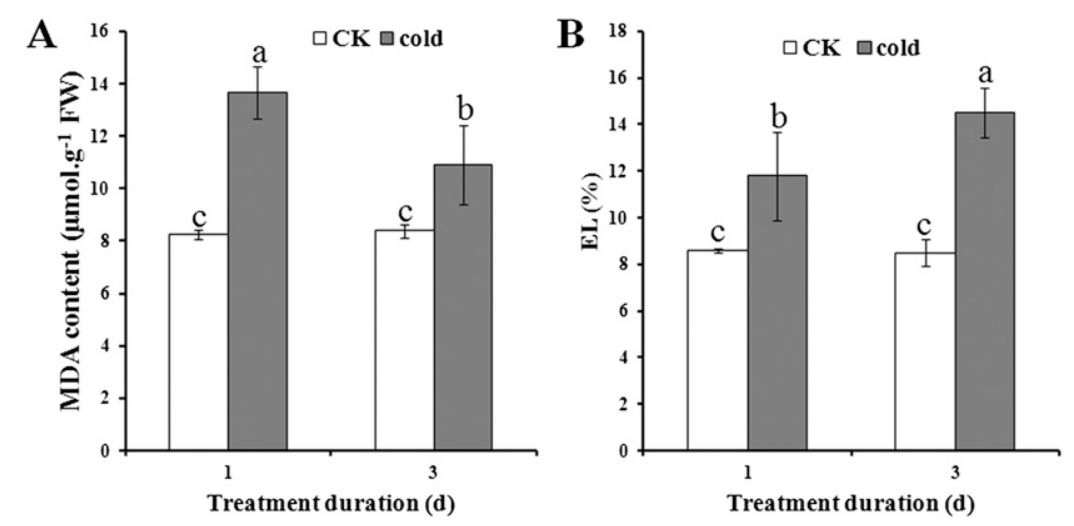

Fig. 2. Changes of cell membrane stability and lipid peroxidation in leaves of bermudagrass under cold stress: (A) malondialdehyde (MDA) content; (B) electrolyte leakage (EL). Experiments were repeated three times, and means stand for average values of MDA content and EL, respectively. Independent-samples $t$ test was used to determine statistical differences. Bars show SD. Different letters indicate statistical difference significance at $P<0.05$ among the treatments. $\mathrm{CK}=$ control; cold $=4{ }^{\circ} \mathrm{C}$ treatment; $\mathrm{FW}=$ fresh weight.
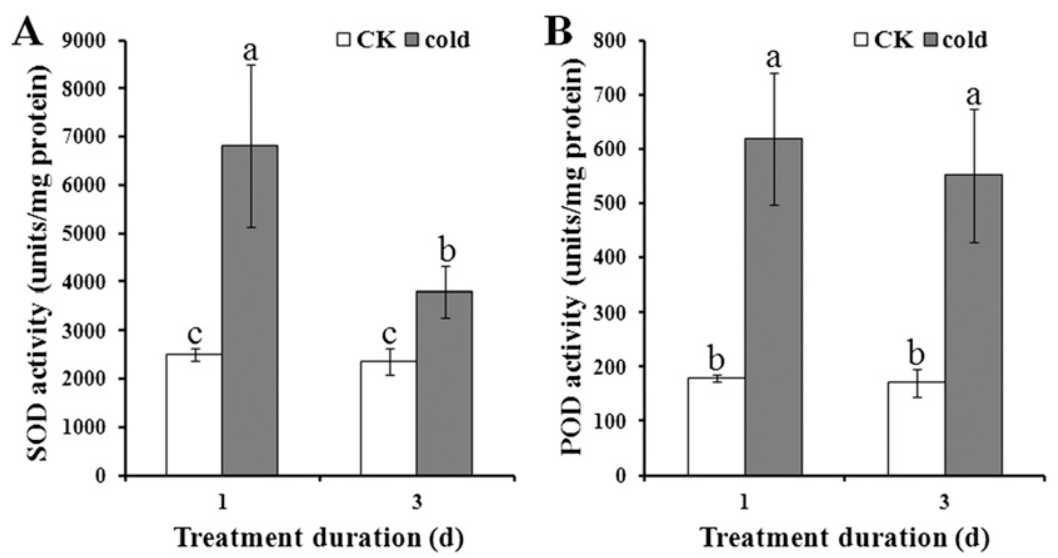

Fig. 3. Changes in antioxidant enzymes activities in leaves of bermudagrass under cold stress: (A) activities of superoxide dismutase (SOD); (B) activities of peroxidase (POD). Experiments were repeated three times, and means stand for average values of activities of SOD and POD, respectively. Independent-samples $t$ test was used to determine statistical differences. Bars show SD. Different letters indicate statistical difference significance at $P<0.05$ among the treatments. $\mathrm{CK}=$ control; cold $=4{ }^{\circ} \mathrm{C}$ treatment; $\mathrm{FW}=$ fresh weight. more soluble sugar at Day 3 than Day 1 when subjected to $4{ }^{\circ} \mathrm{C}$ temperature conditions.

$M n S O D$ gene expression was induced after $1 \mathrm{~h}$, reached the first peak at Hour 3, then decreased at Hour 6 and was the lowest at Hour 12. Bermudagrass had upregulated $M n S O D$ gene expression after $12 \mathrm{~h} 4{ }^{\circ} \mathrm{C}$ treatment and the highest level at Hour 72 after cold treatment (Fig. 5B). The transcripts of $P O D$ gene peaked at Hour 1 after cold treatment (Fig. 5C). Generally there was no significant difference in POD activity within other measuring times. The $A P X$ gene was induced to express at Hour 48 and reached the highest levels at Hour 72 under cold treatment (Fig. 5D). CAT gene expression was downregulated after $1 \mathrm{~h}$ (Fig. 5E).

\section{Discussion}

As a critical environmental factor, cold can affect physiological and biochemical alterations in plants. Many studies have revealed that cell membrane systems are the major sites of freezing injury in plants (Steponkus, 1984). Simultaneously, it has been established that cold-induced membrane injury results mainly from severe dehydration (Steponkus, 1984; Steponkus et al., 1993). Cell membrane stability was widely used as a measure of cellular damage induced by abiotic stress (Saneoka et al., 2004). The EL technique was applied to determine damage to cell membrane (Bajji et al., 2002). This method is based on determination of electrolytes exuding out from injured tissues into distilled water and the degree of injury evaluation (Prášil and Zámečník, 1998). It was illustrated that EL was significantly increased in wheat leaves under salinity stress (AbdelFattah et al., 2011) and in Coffea plants under cold stress (Campos et al., 2003). In our study, a significant increase in EL was observed in wild bermudagrass subjected to cold stress when compared with the control (Fig. 2B), suggesting that loss of membrane stability might result in increased solute leakage.

MDA content is often used as an indicator to evaluate oxidative damage induced by abiotic stress (Davey et al., 2005). It was reported that MDA content was dramatically increased in Coffea plants after chilling (Campos et al., 2003). The results demonstrated a remarkable increase in MDA content in leaf tissues at Days 1 and 3 after cold treatment (Fig. 2A), indicating that cold stress affected oxidative lipid injury. Particularly, it should be noted that the MDA levels were 2fold higher at Day 1 than at Day 3, and this trend whereby MDA content decreased with extension of processing time (length) of cold stress needs to be further investigated. 


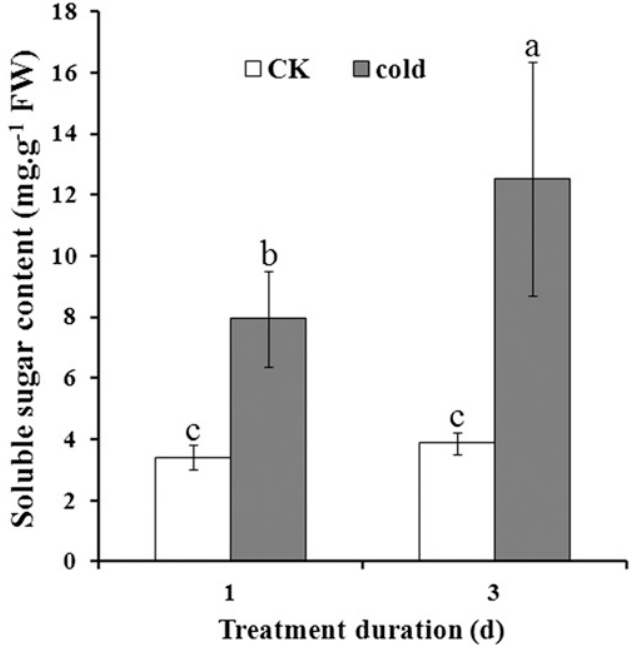

Fig. 4. Changes in soluble sugar content in leaves of bermudagrass under cold stress. Experiments were repeated three times, and means stand for average values of content of soluble sugar. Independent-samples $t$ test was used to determine statistical differences. Bars show SD. Different letters indicate statistical difference significance at $P<0.05$ among the treatments. $\mathrm{CK}=$ control; cold $=4{ }^{\circ} \mathrm{C}$ treatment; $\mathrm{FW}=$ fresh weight.
Abiotic stress, precisely cold, can induce generation of ROS (Shen et al., 2000). ROS can be scavenged by antioxidant enzymes such as SOD, POD, and CAT (Hu et al., 2012). Fu and Huang (2001) reported that activities of antioxidant enzymes in kentucky bluegrass (Poa pratensis) and tall fescue (Festuca arundinacea) were significantly increased after full drought stress (Fu and Huang, 2001). SOD is generally considered as a key enzyme as a result of its scavenging activity on toxic superoxide radicals produced under stressful conditions by conversion of superoxide anions to $\mathrm{O}_{2}$ and $\mathrm{H}_{2} \mathrm{O}_{2}$. Previous reports have demonstrated that over expression of $M n S O D$ and FeSOD could enhance plant tolerance to oxidative stress (Bowler et al., 1991; Camp et al., 1996) and that the activity of SOD is closely related to water, freezing, and salt resistance (Mckersie et al., 1993, 1996; Meloni et al., 2003). In this study, it was noted that the SOD activity increased remarkably after treatment at $4{ }^{\circ} \mathrm{C}$ for Days 1 and 3 (Fig. 3A). These results implied that SOD activity could be induced by ROS production under cold stress. Alternatively, POD depletes ROS and is crucial in $\mathrm{H}_{2} \mathrm{O}_{2}$ degradation (Zhang et al., 2007). The results demonstrated that POD activity was significantly higher under low temperature at Days 1 and 3 than the control (Fig. 3B), illustrating that the increase of POD activity was related to the
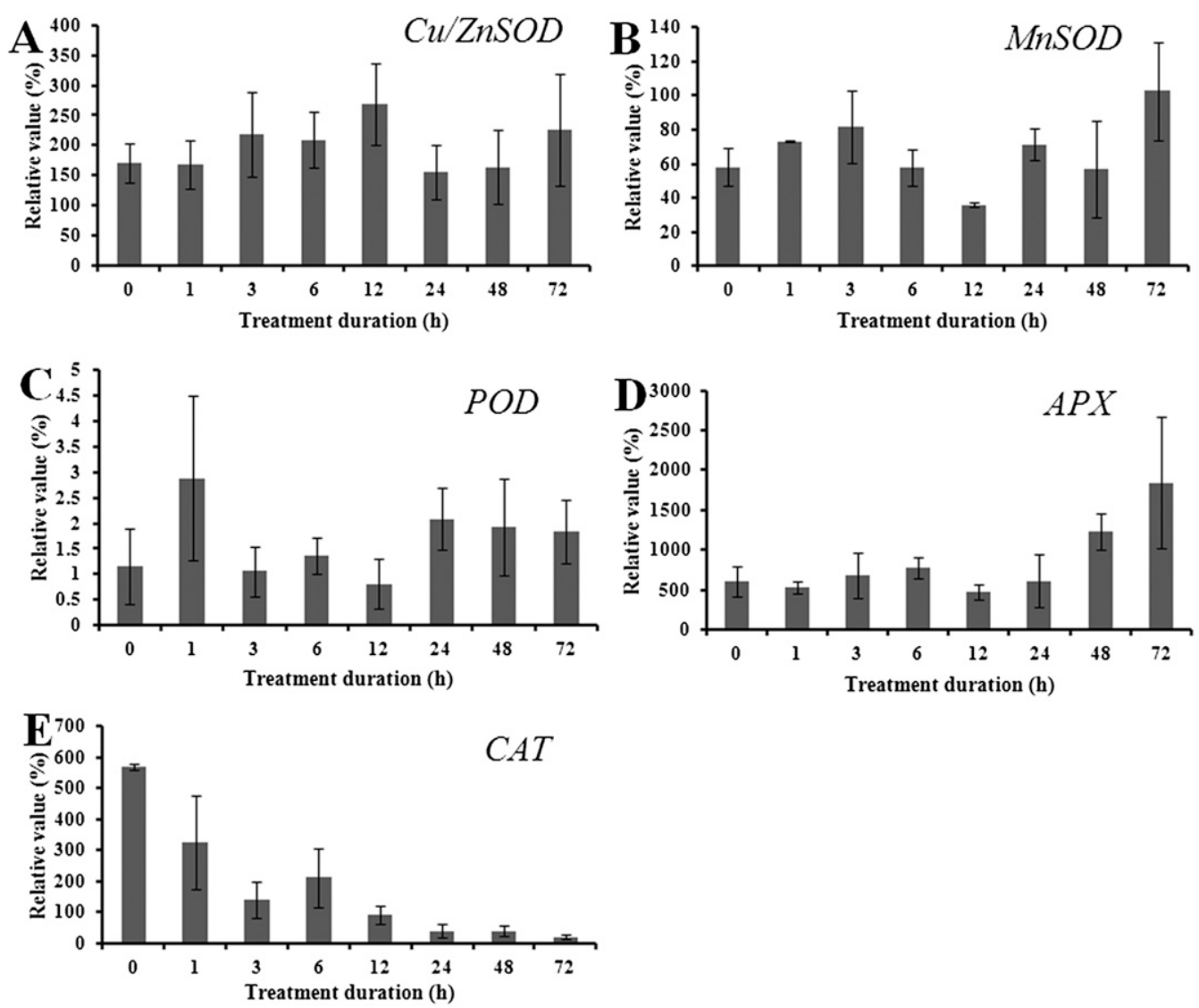

Fig. 5. Expression of antioxidant enzymes genes in leaves of bermudagrass under cold stress: (A) expression of $C u / Z n S O D,(\mathbf{B})$ expression of $M n S O D,(\mathbf{C})$ expression of $P O D,(D)$ expression of $A P X$, (E) expression of $C A T$. Total RNA were isolated from leaves treated at $4{ }^{\circ} \mathrm{C}$ for $1,3,6,12,24,48$, and $72 \mathrm{~h}$, respectively. Quantitative real-time polymerase chain reaction was repeated three times. Independent-samples $t$ test was used to determine statistical differences. Bars show SD. 
antioxidant mechanism of bermudagrass resistance against cold stress. Sugars are regarded as a crucial factor in cold tolerance (Sasaki et al., 1996). In this study, soluble sugar contents were remarkably elevated under cold stress and the contents of soluble sugars at Day 3 were twice as higher as that of Day 1 (Fig. 4). These results suggested that sugars are necessary for cold tolerance in bermudagrass; this can be illustrated by the accumulation of soluble sugars, which positively correlated with low-temperature treatment length.

Antioxidant enzyme activities such as SOD, POD, and APX in bermudagrass under cold stress were significantly increased; therefore, it was necessary to study the expression of genes responsible for encoding these enzymes. There are multiple genes encoding SODs; in addition, different isoenzymes of SOD are specifically localized in chloroplasts, mitochondria, peroxisomes, and cytosol (Mittler, 2002; Sunkar et al., 2006). FeSOD was located in chloroplasts, MnSOD in mitochondria and peroxisomes (Río et al., 2003), and $\mathrm{Cu} / \mathrm{ZnSOD}$ in chloroplasts and the cytosol of higher eukaryotes (Liu et al., 2013). The results indicated that both $M n S O D$ and $C u / Z n S O D$ genes were up-regulated by cold treatment, but expression levels of $C u / Z n S O D$ were much higher than that of $M n S O D$ (Fig. $5 \mathrm{~A}$ and B). Similar results were reported in $P O D$ and $A P X$ expression. Both $P O D$ and $A P X$ were up-regulated with increase in cold treatment time (Fig. $5 \mathrm{C}$ and D). These results suggested that antioxidant enzyme activities may closely correlate with the expression of their relative genes.

CAT is also an enzyme that functions in $\mathrm{H}_{2} \mathrm{O}_{2}$ degradation, which maintains hydrogen peroxide homeostasis in plants (Yang and Poovaiah, 2002). A striking observation was noted when expression of $C A T$ was significantly down-regulated after low-temperature treatment (Fig. 5E). This result was beyond our prediction. According to previous research, changes of CAT under abiotic stress displayed variation. CAT activity increased under lead stress (Li et al., 2012). It was also found that it significantly increased in maize (Zea mays) seedling under chilling condition (Prasad, 1997). However, a decrease was observed in zucchini squash (Cucurbita pepo cv. Elite) and other plants (Wang, 1995). Studies have indicated that CAT can be photo-inactivated and its activity levels quickly lowered under stress through translation inhibition (Dat et al., 2000). This might explain why $C A T$ genes are down-regulated; however, the underlying reasons need to be demonstrated further.

\section{Literature Cited}

Abdel-Fattah, G.M., A.H. Ibrahim, S.M. Al-Amri, and A.E. Shokr. 2011. Arbuscular mycorrhizal fungi and spermine alleviate the adverse effects of salinity stress on electrolyte leakage and productivity of wheat plants. Austral. J. Crop Sci. 51:261-276.

Anderson, J., C. Taliaferro, M. Anderson, D. Martin, and A. Guenzi. 2005. Freeze tolerance and low temperature-induced genes in bermudagrass plants. USGA Turfgrass Environ. Res. Online 4:1-7. Ao, P., Z. Li, and D. Fan. 2013. Involvement of antioxidant defense system in chill hardening-induced chilling tolerance in Jatropha curcas seedlings. Acta Physiol. Plant. 35:153-160.

Asada, K. 2006. Production and scavenging of reactive oxygen species in chloroplasts and their functions. Plant Physiol. 141:391-396.

Baek, K.H. and D.Z. Skinner. 2003. Alteration of antioxidant enzyme gene expression during cold acclimation of near-isogenic wheat lines. Plant Sci. 165:1221-1227.

Bajji, M., J.M. Kinet, and S. Lutts. 2002. The use of the electrolyte leakage method for assessing cell membrane stability as a water stress tolerance test in durum wheat. Plant Growth Regulat. 36:6170.

Bowler, C., L. Slooten, S. Vandenbranden, R. De Rycke, J. Botterman, C. Sybesma, M. Van Montagu, and D. Inzé. 1991. Manganese superoxide dismutase can reduce cellular damage mediated by oxygen radicals in transgenic plants. EMBO J. 10:1723-1732.

Brian, D.P., A.P. Linda, Y. Chen, and G. Douglas. 1984. An inhibitor of catalase induced by cold in chilling-sensitive plants. Plant Physiol. 76:1014-1018.

Camp, W.V., K. Capiau, M.V. Montagu, D. Inze, and L. Slooten. 1996. Enhancement of oxidative stress tolerance in transgenic tobacco plants overproducing Fe-superoxide dismutase in chloroplasts. Plant Physiol. 112:1703-1714.

Campos, P.S., V. Quartin, J.C. Ramalho, and M.A. Nunes. 2003. Electrolyte leakage and lipid degradation account for cold sensitivity in leaves of Coffea sp. plants. J. Plant Physiol. 160:283-292.

Chance, B. and A.C. Maehly. 1955. Assay catalases and peroxidases. Methods Enzymol. 2:764-768.

Chen, L., H. Zhong, F. Ren, Q. Guo, and X.P. Hu. 2011. A novel coldregulated gene, COR25, of Brassica napus is involved in plant response and tolerance to cold stress. Plant Cell Rpt. 30:463-471.

Dat, J., S. Vandenabeele, E. Vranová, M. Van Montagu, D. Inzé, and F. Van Breusegen. 2000. Dual action of the active oxygen species during plant stress responses. Cell. Mol. Life Sci. 57:779-795.

Davey, M.W., E. Stals, B. Panis, J. Keulemans, and R.L. Swennen. 2005. High-throughput determination of malondialdehyde in plant tissues. Ann. Biochem. 347:201-207.

Fu, J.M. and B. Huang. 2001. Involvement of antioxidants and lipid peroxidation in the adaptation of two cool-season grasses to localized drought stress. Environ. Exp. Bot. 45:105-114.

Giannopolitis, C.N. and S.K. Ries. 1977. Superoxide dismutases: II. Purification and quantitative relationship with water-soluble protein in seedings. Plant Physiol. 59:315-318.

Guo, H., S. Gao, F. Zhao, and F. Li. 2004. Effects of cold acclimation on several enzyme activities in Euonymus radicans 'Emorald \& Gold' and its relation to semi-lethal temperature. For. Stud. China 6:10-17.

Gupta, A.S., R.P. Webb, A.S. Holaday, and R.D. Allen. 1993. Overexpression of superoxide dismutase protects plants from oxidative stress. Plant Physiol. 103:1067-1073.

Heath, R.L. and L. Packer. 1968. Photoperoxidation in isolated chloroplasts: I. Kinetics and stoichiometry of fatty acid peroxidation. Arch. Biochem. Biophys. 125:189-198.

Hoagland, D.R. and D.I. Arnon. 1950. The water-culture method for growing plants without soil. California Agr. Expt. Sta. Circ. 347.

Hou, Y., Z. Guo, Y. Yi, H. Li, and H. Li. 2010. Effects of cold acclimation and exogenous pytohormone abscisic acid treatment on physiological indicators of winterness wheat. J. Plant Sci. 5:125-136. Hu, L., H. Li, H. Pang, and J. Fu. 2012. Responses of antioxidant gene, protein and enzymes to salinity stress in two genotypes of perennial ryegrass (Lolium perenne) differing in salt tolerance. J. Plant Physiol. 169:146-156.

Hughes, M.A. and M.A. Dunn. 1996. The molecular biology of plant acclimation to low temperature. J. Expt. Bot. 47:291-305.

Kayihan, C., F. Eyidogan, N. Afsar, H.A. Oktem, and M. Yucel. 2012. $\mathrm{Cu} / \mathrm{Zn}$ superoxide dismutase activity and respective gene expression during cold acclimation and freezing stress in barley cultivars. Biol. Plant. 56:693-698.

Kono, Y. and I. Fridovich. 1982. Superoxide radical inhibits catalase. J. Biol. Chem. 257:5751-5754.

Levitt, J. 1980. In responses of plants to environmental stress. Vol. 1: Chilling, freezing, and high temperature stress, p. 137-141. In: Levitt, J. (ed.). Freezing resistance-Types, measurement and changes. Academic Press, New York, NY.

Li, H., H. Luo, D. Li, T. Hu, and J. Fu. 2012. Antioxidant enzyme activity and gene expression in response to lead stress in perennial ryegrass. J. Amer. Soc. Hort. Sci. 137:80-85. 
Liu, W., K. Yu, T. He, F. Li, D. Zhang, and J. Liu. 2013. The low temperature induced physiological responses of avena nuda L., a coldtolerant plant species. Scientific World J. 2013:1-7.

Luo, Y., H. Tang, and Y. Zhang. 2011. Production of reactive oxygen species and antioxidant metabolism about strawberry leaves to low temperatures. J. Agr. Sci. 3:89-96.

Mckersie, B.D., S.R. Bowley, E. Harjanto, and O. Leprince. 1996. Water-deficit tolerance and field performance of transgenic alfalfa overexpressing superoxide dismutase. Plant Physiol. 111:11771181.

Mckersie, B.D., Y. Chen, M. de Beus, S.R. Bowley, C. Bowler, D. Inze, K. D'Halluin, and J. Botterman. 1993. Superoxide dismutase enhances tolerance of freezing stress in transgenic alfalfa (Medicago sativa L.). Plant Physiol. 103:1155-1163.

Meloni, D.A., M.A. Oliva, C.A. Martinez, and J. Cambraia. 2003. Photosynthesis and activity of superoxide dismutase, peroxidase and glutathione reductase in cotton under salt stress. Environ. Exp. Bot. 49:69-76.

Mittler, R. 2002. Oxidative stress, antioxidants and stress tolerance. Trends Plant Sci. 7:405-410.

Mohammadian, M.A., Z.K. Largani, and R.H. Sajedi. 2012. Quantitative and qualitative comparison of antioxidant activity in the flavedo tissue of three cultivars of citrus fruit under cold stress. Austral. J. Crop Sci. 6:402-406.

Prasad, T.K. 1997. Role of catalase in inducing chilling tolerance in pre-emergent maize seedlings. Plant Physiol 114:1369-1376.

Prášil, I. and J. Zámečník. 1998. The use of a conductivity measurement method for assessing freezing injury. Environ. Exp. Bot. 40:1-10.

Río, L.A., L.M. Sandalio, D.A. Altomare, and B.A. Zilinskas. 2003. Mitochondrial and peroxisomal manganese superoxide dismutase: Differential expression during leaf senescence. J. Expt. Bot. 54:923933.

Saneoka, H., R.E.A. Moghaieb, G.S. Premachandra, and K. Fujita 2004. Nitrogen nutrition and water stress effects on cell membrane stability and leaf water relations in Agrostis palustris Huds. Environ. Exp. Bot. 52:131-138.

Sasaki, H., K. Ichimura, and M. Oda. 1996. Changes in sugar content during cold acclimation and deacclimation of cabbage seedlings. Ann. Bot. (Lond.) 78:365-369.

Shen, W., K. Nada, and S. Tachibana. 1999. Effect of cold treatment on enzymic and nonenzymic antioxidant activities in leaves of chilling- tolerant and chilling-sensitive cucumber (Cucumis sativus L.) cultivars. J. Jpn. Soc. Hort. Sci. 68:967-973.

Shen, W., K. Nada, and S. Tachibana. 2000. Involvement of polyamines in the chilling tolerance of cucumber cultivars. Plant Physiol. 124:431-439.

Södergren, E. 2000. Lipid peroxidation in vivo. Doctor diss., Univ. Uppsala, Uppsala, Sweden.

Steponkus, P.L. 1984. Role of the plasma membrane in freezing injury and cold acclimation. Annu. Rev. Plant Physiol. 35:543-584.

Steponkus, P.L., M. Uemura, and M.S. Webb. 1993. Membrane destabilization during freeze-induced dehydration. Curr. Topics Plant Physiol. 10:37-47.

Sunkar, R., A. Kapoor, and J.K. Zhu. 2006. Posttranscriptional induction of two $\mathrm{Cu} / \mathrm{Zn}$ superoxide dismutase genes in Arabidopsis is mediated by downregulation of miR398 and important for oxidative stress tolerance. Plant Cell 18:2051-2065.

Wang, C. 1995. Effect of temperature preconditioning on catalase, peroxidase, and superoxide dismutase in chilled zucchini. Postharvest Biol. Technol. 5:67-76.

Wang, L. and Q. Cai. 2011. Impacts of cold stress on activities of sod and pod of rice at seedling stage. Hunan Agr. Sci 11:56-58, 62.

Whitlow, T.H., N.L. Bassuk, T.G. Ranney, and D.L. Reichert. 1992. An improved method for using electrolyte leakage to assess membrane competence in plant tissues. Plant Physiol. 98:198-205.

Yan, W., L. Bai, L. Zhang, G. Chen, J. Fan, X. Gu, W. Cui, and Z. Guo. 2010. Comparative study for cold acclimation physiological indicators of Forythia mandshurica Uyeki and Forsythia viridissima Indl. Middle-East J. Sci. Res. 6:556-562.

Yang, T. and B.W. Poovaiah. 2002. Hydrogen peroxide homeostasis: Activation of plant catalase by calcium calmodulin. Proc. Natl. Acad. Sci. USA 99:4097-4102.

Zhang, F., Y. Wang, Z. Lou, and J. Dong. 2007. Effect of heavy metal stress on antioxidative enzymes and lipid peroxidation in leaves and roots of two mangrove plant seedlings (Kandelia candel and Bruguiera gymnorrhiza). Chemosphere 67:44-50.

Zhang, X., E.H. Ervin, and A.J. LaBranche. 2006. Metabolic defense responses of seeded bermudagrass during acclimation to freezing stress. Crop Sci. 46:2598-2605.

Zhou, S. 1996. The lawn and the human environment. 1st Ed. Sichuan Sci. Technol. Press, Chengdu, China.

Zhu, J., C. Dong, and J. Zhu. 2007. Interplay between cold-responsive gene regulation, metabolism and RNA processing during plant cold acclimation. Curr. Opin. Plant Biol. 10:290-295. 